\title{
Internet Video Calling and Desktop Sharing (VCDs) as an Emerging Research Method for Exploring Pedagogical Reasoning in Lesson Planning
}

\section{Profiling Emerging Research Innovations}

\author{
Elizabeth Hidson \\ Senior Lecturer, University of Sunderland, Sunderland, UK \\ elizabeth.hidson@sunderland.ac.uk
}

\begin{abstract}
This article presents the specific case of video calling and desktop sharing (VCDs) used in a small-scale doctoral study exploring the lesson planning processes of teachers as a result of a national curriculum change. Accessing the participants' actions and live think-aloud exposition of their pedagogical practices also generated dialogue as new data. The study set out to explore how pedagogical content knowledge was enacted through pedagogical reasoning when participant teachers planned Computing lessons. Two central case studies captured using VCDS are shared. One presents a dialogic research interview which developed a shared understanding of the impact of the curriculum change on one teacher's practices. The second case study shows the potential of VCDS to capture the verbalised thoughts and observable actions of a second teacher preparing to teach new programming skills. The video data collected provided a rich audio-visual record of the lesson planning process as it happened. This article shares the approach taken, exemplifies the data captured and reflects on vCDS as a method for exploring teachers' pedagogical reasoning. It concludes that, depending on the nature of the research question, vCDS may be justified as more suitable than face-to-face, artefact-based interviews.
\end{abstract}

\section{Keywords}

emerging research innovations - video calling - desktop sharing - digital research methods - pedagogical reasoning - lesson planning 


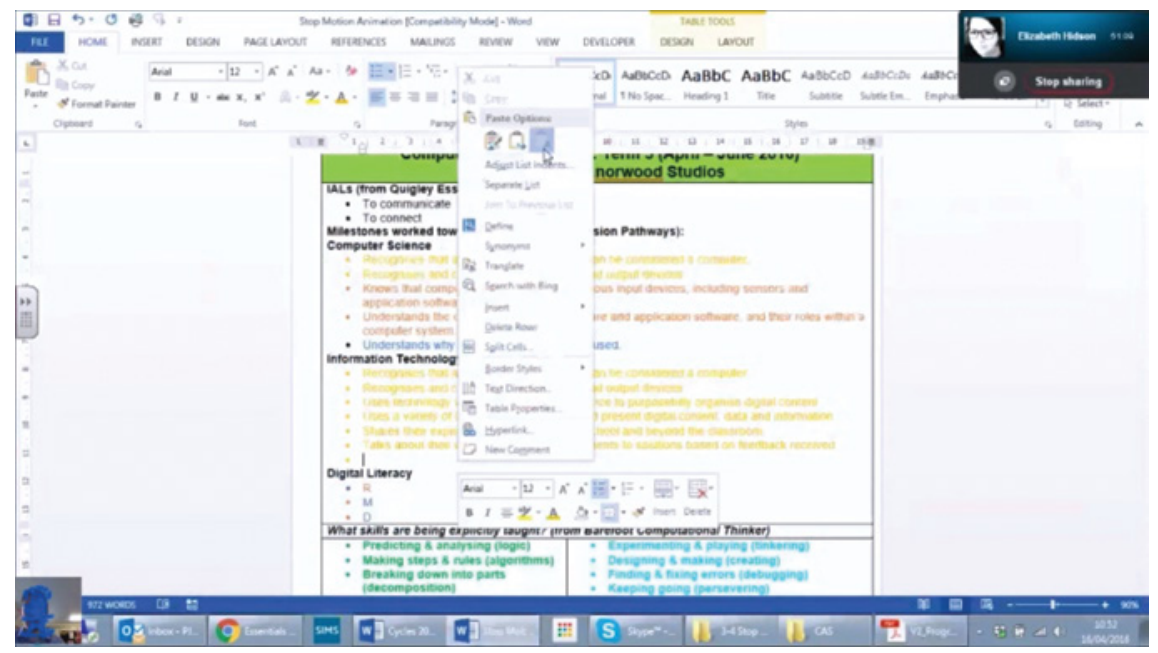

FEATURE Elizabeth Hidson's article comprises two videos, which can be viewed here.

- This article is part of the special topic 'Profiling Emerging Research Innovations', edited by Elaine Khoo.

\section{$1 \quad$ Background}

In 2014, the English national curriculum programme of study (Department for Education, 2013) for all schoolchildren finally changed from Information and Communications Technology (ICT) to Computing, representing a muchdiscussed disciplinary shift for in-service teachers (Woollard, 2018). Teachers employed to teach ICT as a school subject tended to have a background more relevant to teaching Information Technology rather than its more abstract and programming-oriented relative Computer Science, which was newly incorporated into the national curriculum underneath the umbrella term 'Computing'. The difference in the two might best be understood as ICT focusing on the use and application of technology and Computer Science focusing on computational systems and programming. The resulting disenfranchisement of the in-service teachers because of their lack of knowledge and experience in the new area led to significant pressure to upskill with sufficient speed to continue in their teaching roles (Sentance, McNicol \& Dorling, 2012). A top-down lack of understanding of the disciplinary differences between these two areas meant that in-service teachers had little time for, or access to professional 
development opportunities, pushing the onus back on them to manage the transition as best they could.

The perceptions of these in-service teachers of the change from ICT to Computing and the way in which they approached the planning of Computing lessons following the curriculum change formed the basis of a small-scale doctoral study, which charted the experiences of nine in-service teachers. The study set out to explore how pedagogical content knowledge was enacted through pedagogical reasoning when participant teachers planned Computing lessons. Using a qualitative embedded multiple case study research design (Yin, 2012) enabled planning to be explored through different lenses, revealing various elements of the pedagogical reasoning process. The participants were systematically selected based on experience and context, which resulted in a geographical spread across England. The data needed to answer the research questions meant that access was required to the teachers at the time when each one was ready to engage in planning, bringing verisimilitude to the process. This was conceptualised in line with Shulman's $(1986,1987)$ process of pedagogical reasoning, focusing in on the teachers' pedagogical content knowledge (PCK) as they sought to plan lessons and sequences of lessons that required an understanding of specific subject matter as well as a knowledge of how to teach this material in a way that learners would be able to engage with. For teachers with limited knowledge of aspects of Computer Science, the challenge to their pedagogical content knowledge came firstly from needing to source the appropriate material to teach and secondly, being able to understand the way that learners would engage with it, and anticipate misconceptions.

Methodologically, triangulating qualitative findings from interviews, observations and documents was appropriate (Patton, 2015). A researcher could interview, observe and explore documentation of all kinds in order to collate and interpret the practical knowledge of teachers (Shulman, 1987). However, the geographic challenges coupled with the time-sensitive nature of the focus meant that face-to-face interviews were not always viable. Given that these ICT teachers were all comfortable with technology, the move to internet calling and desktop sharing felt like a minor methodological adjustment: pragmatic given the circumstances and one that was fully in line with the positionality of the researcher. As a former ICT teacher, the researcher was closely positioned to the participants on several dimensions: through similar professional skills and experiences as well as an equal level of competence and confidence in digital and visual approaches to teaching and learning. Using this approach allowed, as per Pink et al. (2016), observation of what the participants were doing through the Skype shared desktop, resulting in a digital workspace with the 
teachers who were happy to work in this way and providing insights into their practice.

Unexpectedly, the literature around the combined use of internet calling with desktop sharing as a research method was sparse. The iterative-inductive approach (O'Reilly, 2009) used in the case study meant that returning to the literature iteratively to develop new lines of enquiry resulted in aligning this approach to the general field of digital and visual methods rather than a specific methodological branch. This article aims to outline the conceptual lens developed to support the use of internet calling and desktop sharing as an emergent research method for the close-to-practice study of pedagogical reasoning. The purpose of this work is to pave the way for VCDS to be seen as discrete research method so that newer researchers, or those interested in making the transition to digital research methods will be able to learn about the methodological heritage of the method as outlined in this study.

\section{Visual Ethnography and Video Methods in Educational Research}

Justifying the use of internet calling and desktop sharing as a research method began by aligning with the visual aspects of the method. The need to 'see' things more clearly invited a visual methodology, allowing a 'new view' with the luxury of meta-analysis and reflection (Lyle, 2003). Using a method so rooted in the visual prompted an ethnographic approach, which "makes visible the many ways in which individuals do not exist alone and how their positions and agency in communities of practice influence their experience in these communities" (Nind, Curtin \& Hall, 2016, p. 140). Savin-Baden and Tombs (2017) highlight a difficulty present in the field of qualitative research about whether such methods can be considered as 'digital visual' or just 'visual' methods but given the importance of locating them methodologically, this pointed overall to a visual ethnography as a positional home for the research. Pink's (2013) seminal work embraces the interrelated influences that shape the practice of visual ethnography, allowing a researcher to bring together the "theoretical and practical elements of visual approaches to learning about and in the world and communicating these to others" (Pink, 2013, p. 6).

The intention had been to use video-stimulated interviews to elicit teachers' tacit knowledge of their own PCK in their lesson planning by jointly observing excerpts and engaging in video-stimulated recall, reflection and dialogue (VSRRD) as developed by Nind, Kilburn and Wiles (2015). This constructivist approach recognised the importance of eliciting knowledge by unpacking individuals' experiences in their lived reality. Video offers rich visual vignettes: a multimodal series of moving images with attendant audio, situated in 
context, albeit offering a restricted view, but one that is far more detailed than just field notes or still images would have allowed. Having participants think out loud in this way was confirmed as an appropriate method to use when studying an individual's interactive thoughts (Reitano, 2006). It was anticipated that triangulation of these various data streams and comparison to the literature would allow as full as range of snapshots of practice (Kind, 2009) as possible within the scope of the study.

An exploration of key features from a selection of studies using video as an interview prompt (Dempsey, 2010; Jones et al., 2009; Lyle, 2003; Moyles, Hargreaves, Merry, Paterson, \& Esarte-Sarries, 2003; Nind et al., 2015) suggested that although different research agendas and interpretive frameworks impacted on the way the method was used, the use of video was central to each. A shared reflective, dialogic experience between researcher and participant seemed to be the key to more recent developments in video-stimulated methods. Most importantly, the Nind et al. (2015) full VSR RD strand had the most consonance with the current methodology as they emphasised that any and all aspects of the interview could be analysed to provide additional detail. The move from solely using video to using a range of multimedia artefacts and relying on the video as much for capture as for the interview meant that a branching approach was taken. Beginning with visual methods led to visual ethnography, then video methods, and then to an embracing of recall, reflection and dialogue that became possible through internet video calling and desktop sharing channelled by this methodological heritage into a discrete research method.

\section{3}

Internet Calling and Desktop Sharing in Educational Research

Internet-mediated research, and the more recent phenomenon of video calling as one example, have been seen incrementally as methodological frontiers for at least a decade (Madge, 2010, cited in Deakin \& Wakefield, 2014; Weller, 2015). The major debates have tended to encompass the differences between online and face-to-face interviewing (c.f. Deakin \& Wakefield, 2014) as well as issues of the theoretical stances towards the use of digital methods. More recent publications have suggested that innovations in digital research methods and tools have been smaller than expected (Halfpenny \& Proctor, 2015), relatively uncommonly used for online data collection (O'Connor \& Madge, 2017) and have produced relatively little debate in relation to their use in online settings (Savin-Baden \& Tombs, 2017). These authors suggest lines of enquiry in relation to digital research methods that seem to focus on bringing offline methods into online spaces, such as interview methods that have been undertaken offline but are now undertaken online. 
The rise of consumer internet-calling technologies such as Skype (initially released in 2003) with subsequent video calling capabilities has led to increasing acceptance of internet telephony itself as a data collection tool (Deakin \& Wakefield, 2014; Mavroudi \& Hadzilacos, 2013; O'Connor \& Madge, 2008; Paulus, Lester \& Dempster, 2014; Weller, 2015). However, desktop sharing has rarely been mentioned in terms of research methods, even where it has been used for research projects (Paulus et al., 2014). The use of video calling and desktop sharing seems to have become integrated ubiquitously for teaching and learning in computer-supported collaborative learning rather than in relation to research methods.

Even in studies that focus, as this study did, on teachers' professional development using digital tools, data collection remained focused on traditional offline interviews (Banegas, 2013; Irvine, 2015; Tanni, 2012), online surveys or questionnaires (Banegas, 2013; Lavine, Greenberg, Chen, Kao, \& Lin, 2012; le Roux \& Loock, 2015; Poyo, 2016) as well as email exchanges of artefacts (Irvine, 2015) despite the relevance of the technology to the research question. One particular study by Tanni (2012) noted the limits that this placed on the kind of data that could be collected on the lesson planning process but did not propose different approaches. What results seems to be a collective missed opportunity to harvest data using the available digital tools.

\section{Internet Video Calling and Desktop Sharing (vCDs) as a Method}

The use of video as a method to examine teachers' practices fit into the research design of the current study as a major data component, with planned triangulation of "converging lines of evidence" (Yin, 2012, p. 13), as warranted in case studies. Video was used to record all live contact with the participants, either physically co-present (via iPad) or remotely through internet video calling (Skype). Skype was offered to participants as an interview medium, and for six of the nine participants was an effective way to proceed. The ability to record the interview was made possible using software tools for video recording and streaming (Evaer and Open Broadcaster), which integrated easily with Skype. Pseudonyms Ben and Alex are used to present two of the participants in the case studies that follow.

Ben was able to share his screen and discuss his planning approach while he was planning a sequence of computing lessons. The Case Study 1 video extract 


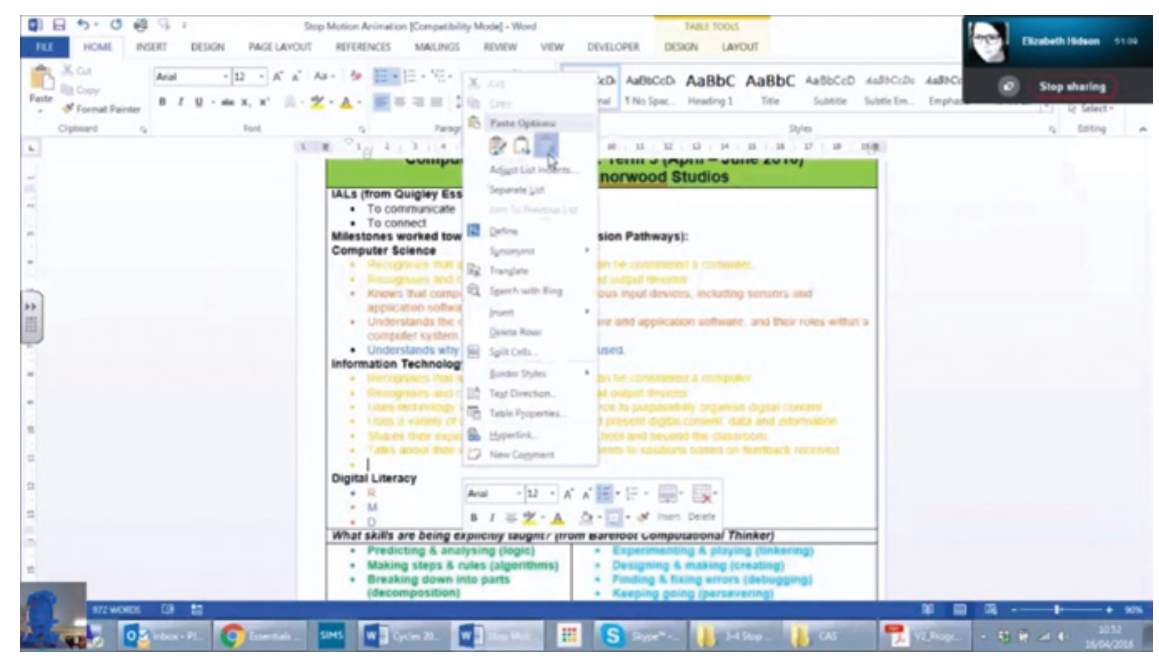

VIDEO 1 The dialogic interview. (See here.)

serves to demonstrate the researcher's view of Ben's desktop in desktop-sharing mode, showing some of the actions that Ben took during the planning session as well as an example of the dialogue between them, shown below. In this extract, Ben explains some comments in his plan, which prompts the researcher to follow up with a comment and a query:

[Ben] As with any new system, we've been blogging for about a year and a half and some teachers take to it more than others and some need a bit more reminding, so I make sure that I put opportunities to blog into the computing plan and show how it can be used in a sort of pedagogical sense then that's erm - that helps them. I don't know if some of them do it more in other subjects, some of them do but some of them don't

[Researcher] That's interesting

[Ben] What's that, blogging?

[Researcher] You influencing practice elsewhere - sorry - I probably should just shut up - I keep having to stop myself from asking you more questions because it's quite interesting stuff but I thought that was interesting

[Ben] I'm fine for you to do that

[Researcher] I just don't want to distract you

[Ben] I distract myself enough - don't worry

[Researcher] I was watching this and I was just thinking are you a particular feeder school to a specific secondary school? 
[Ben] No, we feed about 4 or 5 - why did that pop in to your head?

[Researcher] It makes me wonder how the local [secondary schools] are coping with the - is there any interplay between the local [primary schools] and secondary transition - to understand what they've done before?

As well as seeing multiple desktop windows being opened, multiple documents referred to, and multiple web searches for illustrative material being carried out, the dialogue captured adds to the richness of data, generating deeper insights into Ben's practice. It is notable that this extract marks the point at which both researcher and participant seemed to embrace the dialogic opportunity of the interview.

This interview was characterised by the teacher's desire to try out a piece of programming code for himself before teaching it to his students in the upcoming lesson. Keen to identify potential learning opportunities from deliberate

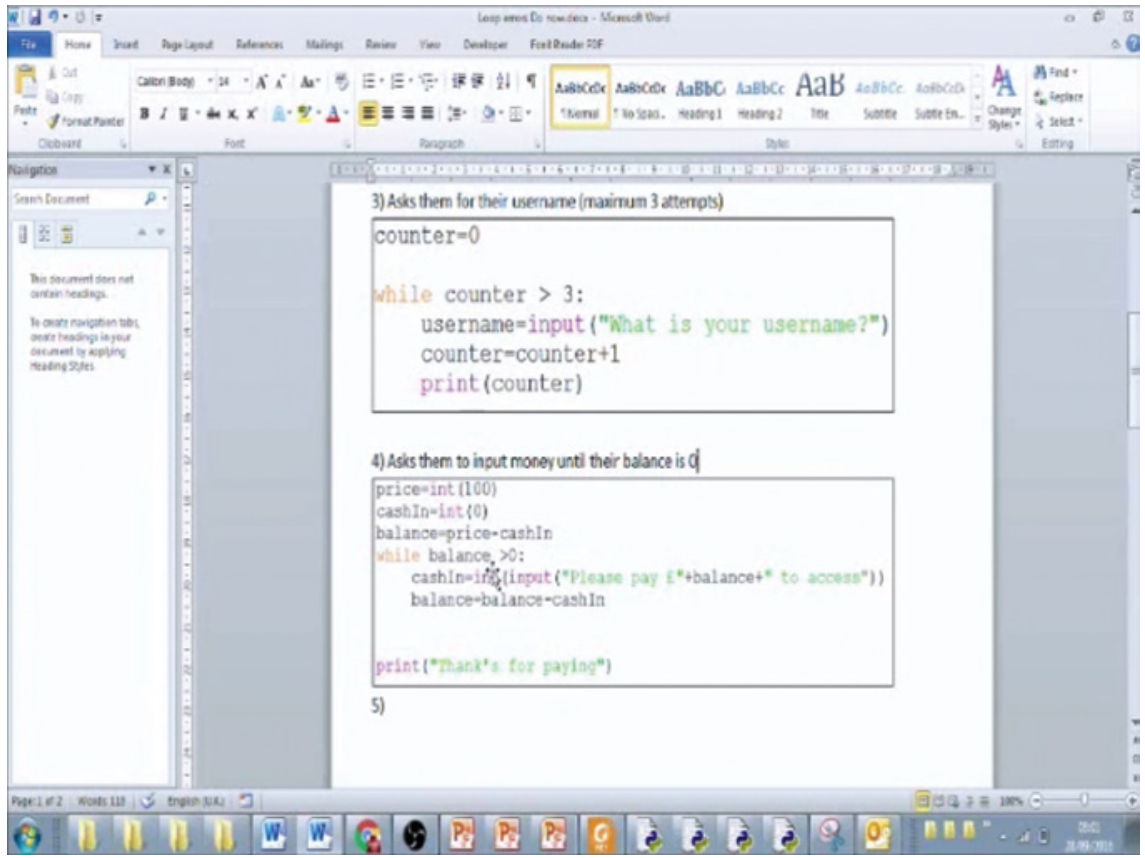

VIDEO 2 The think-aloud interview. (See here.) 
errors in the code, Alex thought through alternative ways that the errors could be represented. In so doing, he drew on his knowledge of his pupils' prior learning, adapting the task based on their characteristics. The Case Study 2 video follows several minutes of Alex's think-aloud trial and error process of developing a program in the Python programming language to simulate feeding coins into a machine to enter to a car park:

[Alex] I wonder if this would work ... what would happen if we just took this and we make this a float to start with and we just check if it's an integer, because that might just work ...

That's fine, ok! ... What happens if we run it and...

I'm not sure that we need the modulus...

That still works...

So the only thing is, I need to strip out this comma, the balance is now $£_{22}$, so that works perfectly...

I think I can give this back to my students and the error that we are going to put in is here...

Later in the planning, Alex's subject knowledge was challenged by an unexpected problem in the code he had been developing for the students' use. Frustrated and unable to work out what the error was, Alex tried several different approaches of increasing difficulty and eventually turned to an online resource to find the answer. However, his concluding comment was telling: if he had struggled to program this, he had concerns that his students would also struggle. The emotional tone of Alex's planning session had changed as he wrestled with the program code and became disheartened until he developed a workaround solution.

Alex's developing subject knowledge confidence had been knocked but his PCK showed new nuances as he needed to rethink his lesson planning. Shulman asserted that the teacher's grasping of an idea to be taught was not a passive act: "the teacher's comprehension requires a vigorous interaction with the ideas" (Shulman, 1986, p. 13). Shulman pre-empted that teachers, especially novice teachers, would not always proceed from a secure comprehension: "some sort of comprehension (or self-conscious confusion, wonder, or ignorance) will always initiate teaching” (Shulman, 1986, p. 14).

\section{Discussion}

Both Alex and Ben's ways of working seemed indicative of their general disposition towards the use of digital tools, to be expected in teachers whose work 
focused on the use of ICT. The ability to multi-task with digital media "with a sense of understanding of the value and possibilities of their use and function" (Savin Baden \& Tombs, 2017, p. xviii) seems here to be bound up with one's identity. Both participant and researcher were open to the affordances of digital tools: one in terms of teaching and the other in terms of research potential.

Every step of both participants' lesson planning was captured through vCDs. They verbalised their purposes, their actions, and their emotional reaction to the process. This window into practice could not have been achieved so effectively without the video and desktop sharing functions. A researcher physically co-located with the participants would have had to sit right next to them and video-record what was happening to gain this level of data quality, which would have given rise to issues of personal space and self-consciousness that were absent from this planning session.

One benefit of this approach is that it generates abundant data that can be revisited, "enabling a richer focus on the minutiae" (Weller, 2015, p. 41). The video data collected became a rich visual record of the lesson planning processes as well as an accurate record of all utterances. Figure 1 illustrates a summary of the desktop sharing method developed by Hidson (2018). The participant and researcher connect through an internet call. This enables two-way dialogue between the researcher and participant. Video can be enabled by each party. The participant chooses to share their desktop, which can then be observed and recorded by the researcher. In practical terms, the recording can be started by the researcher as soon as the connection is made, which will then record all audio and video during the session. Once the desktop is shared, the video stream of the participant is minimised and can be hidden to avoid distraction. The researcher has full access to viewing everything on the participant's computer

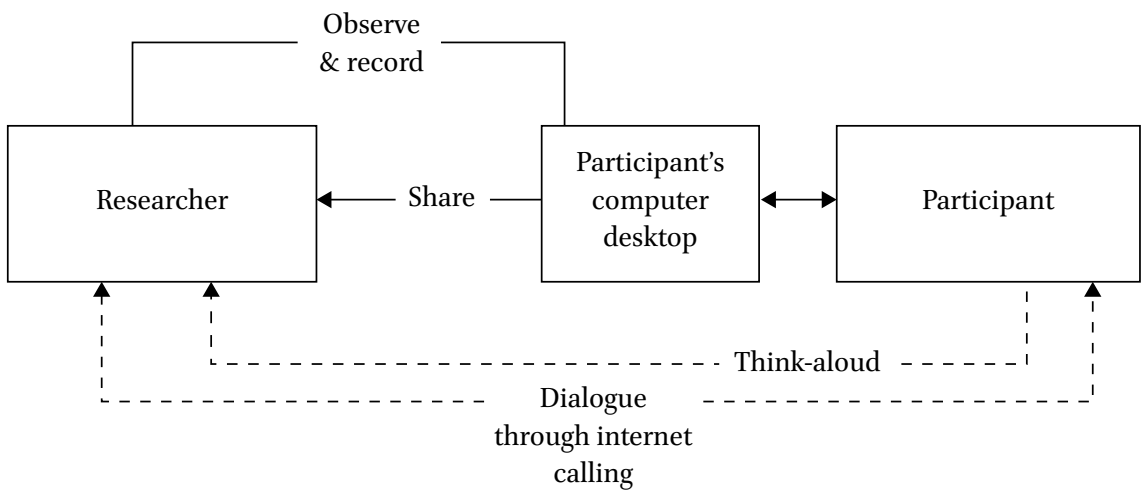

FIGURE 1 Model of desktop sharing method (Hidson, 2018) 
desktop, which enables the researcher to observe all actions. The participant engages in two-way dialogue with the researcher as in Case Study 1, or in a think-aloud explanation of what they are doing as in Case Study 2.

In this study, the actions observed through the desktop-sharing method included participants creating lesson artefacts and resources, locating saved materials for re-use or review, use of internet search engines to locate text or multimedia information, and trialling methods for use in the classroom, such as developing a programming technique in advance of teaching it to the class. One additional action taken by participants was that of illustrating something they had referred to by locating it in their own archives or on the internet, allowing an insight into wider influences and practices than might otherwise have been gleaned through the sole use of interview questions.

\section{Concluding Comments: Building a Case for VCDS as a Research Method}

The methodological contributions of this research involve the use of VCDS for researching teacher practices. The research was initiated by "questions, problems [and] challenges ... identified and formed by the needs of practice and practitioners" (Gray, 1998, p. 84), which also provided the stimulus to use methods that could capture those practices in an authentic manner.

Another contribution of this study's methodological approach is the considerable extent to which it enabled the breadth and authenticity of the conversations anchored around the lesson planning process undertaken for the study. Participants were comfortable to talk at length while they were engaging in the planning process. Being engaged in the act of planning, mediated through technology, seemed to have an enabling effect. This is not a new phenomenon for online interviewing, as it confirms the findings of Weller (2015), whose study used online interviewing as part of a longitudinal study with young people: 'the lack of 'pressure of presence' and the encroachment of the researcher on the personal territory of participants aided rapport and disclosure" (Weller, 2015, p. 44). The current study, however, reports a further advantage by using the affordances of the desktop-sharing function to share working processes combined with a think-aloud and/or dialogic strand. Further investigation of this method is strongly recommended in terms of an initial systematic review encompassing fields beyond education.

This article concludes that VCDS as an online research method in its own right, depending on the nature of the research question, may be justified as more suitable than face-to-face, artefact based interviews. 


\section{References}

Banegas, D. L. (2013). E LT through videoconferencing in primary schools in Uruguay: First steps. Innovation in Language Learning and Teaching, 7(2), 179-188. https:// www.doi.org/10.1080/17501229.2013.794803.

Deakin, H., \& Wakefield, K. (2014). Skype interviewing: Reflections of two PhD researchers. Qualitative research, 14(5), 603-616.

Dempsey, N. P. (2010). Stimulated recall interviews in ethnography. Qualitative Sociology, 33(3), 349-367. https://doi.org/10.1007/s11133-010-9157-x.

Department for Education. (2013). National curriculum in England: computing programmes of study. https://www.gov.uk/government/publications/national -curriculum-in-england-computing-programmes-of-study/.

Gray, C. (1998). Inquiry through practice: Developing appropriate research strategies. In P. Strandman (Ed.), No Guru, No Method? Discussion on Art and Design Research. (pp. 82-95). Research Institute, University of Art and Design Helsinki.

Halfpenny, P., \& Procter, R. (Eds.). (2015). Innovations in digital research methods. Sage. Hidson, E. F. (2018). Challenges to Pedagogical Content Knowledge in lesson planning during curriculum transition: a multiple case study of teachers of ICT and Computing in England [Unpublished doctoral thesis]. Durham University.

Irvine, T. M. (2015). Pinned: A qualitative study of teacher experiences of interfacing with online resources for lesson planning [Unpublished doctoral thesis]. Capella University.

Jones, S., Tanner, H., Kennewell, S., Parkinson, J., Denny, H., Anthony, C., Beauchamp, G., Jones, B., Lewis, H., \& Loughran, A. (2009). Using Video Stimulated Reflective Dialogue to support the development of ICT based pedagogy in Mathematics and Science. The Welsh Journal of Education, 14(2), 63-77.

Kind, V. (2009). Pedagogical content knowledge in science education: potential and perspectives for progress. Studies in Science Education, 45(2), 169-204. https://www .doi.org/10.1080/03057260903142285.

Lavine, R., Greenberg, J., Chen, J., Kao, K., \& Lin, Y. T. (2012). East meets west: a virtual international teacher education initiative between Taiwan and the U.S. Journal of the International Society for Teacher Education, 16(1), 35-45.

le Roux, P., \& Loock, M. (2015, December 4-5). The impact and opportunities of e-tutoring in a challenged socio-economic environment. [Paper presentation]. 2015 International Conference on Computing, Communication and Security (ICCCS), Pamplemousses, Mauritius. IEEE. https://www.doi.org/10.1109/CCCS.2015.7374167.

Lyle, J. (2003). Stimulated recall: a report on its use in naturalistic research. British Education Research Journal, 29(6), 861-878.

Mavroudi, A. and Hadzilacos, T., 2013. Group-work in the design of complex adaptive learning strategies. Journal of Interactive Media in Education, 2013(2), 1-20. https:// www.doi.org/10.1080/17501229.2013.794803. 
Moyles, J., Hargreaves, L., Merry, R., Paterson, F., \& Esarte-Sarries, V. (Eds.). (2003). Interactive teaching in the primary school: digging deeper into meanings. Open University Press.

Nind, M., Curtin, A., \& Hall, K. (2016). Research methods for pedagogy. Bloomsbury.

Nind, M., Kilburn, D., \& Wiles, R. (2015). Using video and dialogue to generate pedagogic knowledge: teachers, learners and researchers reflecting together on the pedagogy of social research methods. International Journal of Social Research Methodology, 18(5), 561-576. https://www.doi.org/10.1080/13645579.2015.1062628.

O'Connor, H., \& Madge, C. (2017). Online interviewing. In Fielding, N., Lee, R. M., \& Blank, G. (Eds), The Sage handbook of online research methods. 416-434. Sage.

O'Reilly, K. (2009). Key concepts in ethnography. Sage.

Patton, M. Q. (2015). Qualitative research and methods: Integrating theory and practice. Sage.

Paulus, T. M., Lester, J. N., \& Dempster, P. G. (2014). Digital tools for qualitative research. Sage.

Pink, S. (2013). Doing Visual Ethnography. Sage.

Pink, S., Horst, H., Postill, J., Hjorth, L., Lewis, T., \& Tacchi, J. (2016). Digital Ethnography: Principles and Practice. Sage.

Poyo, S. R. (2016). Transforming traditional practices of teacher preparation to meet changing needs of digital learners: a first step intervention by assessing and addressing needs of pre-service teachers in a dual learning environment [Unpublished doctoral thesis]. Duquesne University.

Reitano, P. (2006, December 10 -13.). The value of video stimulated recall in reflective teaching practices. [Paper presentation]. Australian Consortium for Social and Political Research Incorporated (ACSPRI) Social Sciences Methodology Conference. Sydney, Australia. https://hdl.handle.net/1959.11/1003.

Savin-Baden, M. \& Tombs, G. (2017). Research Methods for Education in the Digital Age. Bloomsbury.

Sentance, S., Dorling, M., McNicol, A., \& Crick, T. (2012, November 8 -9). Grand challenges for the UK: upskilling teachers to teach computer science within the secondary curriculum. [Paper presentation]. WiPCSE 7 th Workshop in Primary and Secondary Computing Education. Hamburg, Germany. https://www.doi.org/10.1145/ 2481449.2481469.

Shulman, L. (1986). Those who understand: Knowledge growth in teaching. Educational Researcher, 15(2), 4-14.

Shulman, L. (1987). Knowledge and Teaching: Foundations of the New Reform. Harvard Educational Review, 57(1), 1-21.

Tanni, M. (2012). Teacher trainees' information acquisition in lesson planning. Information Research, 17 (3, 1-19).

Weller, S. (2015). The potentials and pitfalls of using Skype for qualitative (longitudinal) interviews. http://eprints.ncrm.ac.uk/3757/1/Susie\%2oWeller.pdf. 
Woollard, J. (2018). Computer studies, information technology, ICT and now computing. In S. Younie, \& P. Bradshaw (Eds.), Debates in Computing and ICT Education (pp. 14-26). Routledge.

Yin, R., (2012). Applications of case study research. (3rd ed.). Sage. 